\title{
TIME TO ACCEPTANCE OF AEROSOL DELIVERY CHAMBER IN HEALTHY DOGS AND CATS
}

\section{OBJECTIVE}

Aerosol medications are commonly recommended for use in dogs and cats, however, anxiety regarding tolerance and compliance to application of the face mask / chamber may be a barrier to clinicians recommending inhalation therapy.

The goal of this study was to evaluate the duration of time required to train a dog or cat to accept the mask / chamber.
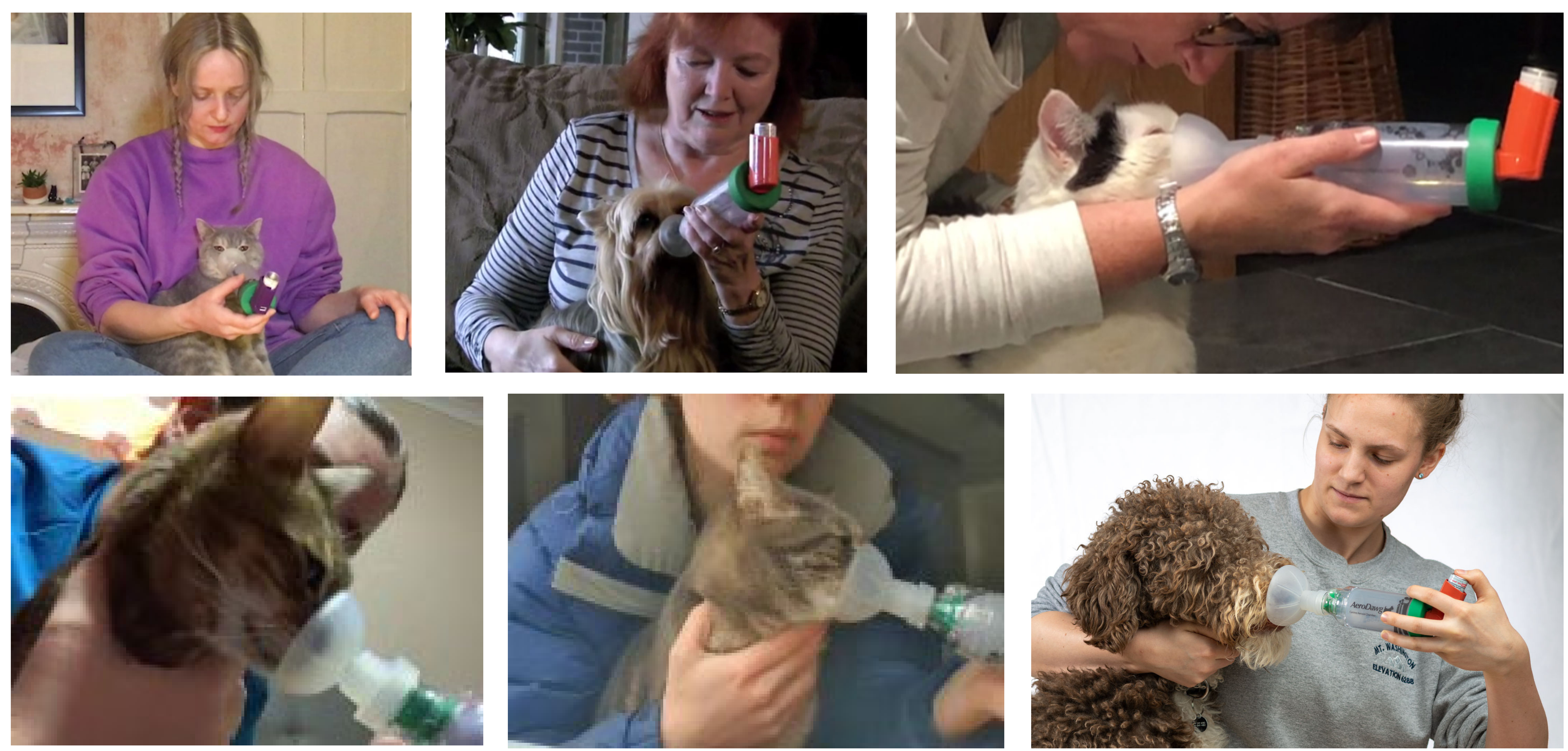

\section{METHODS}

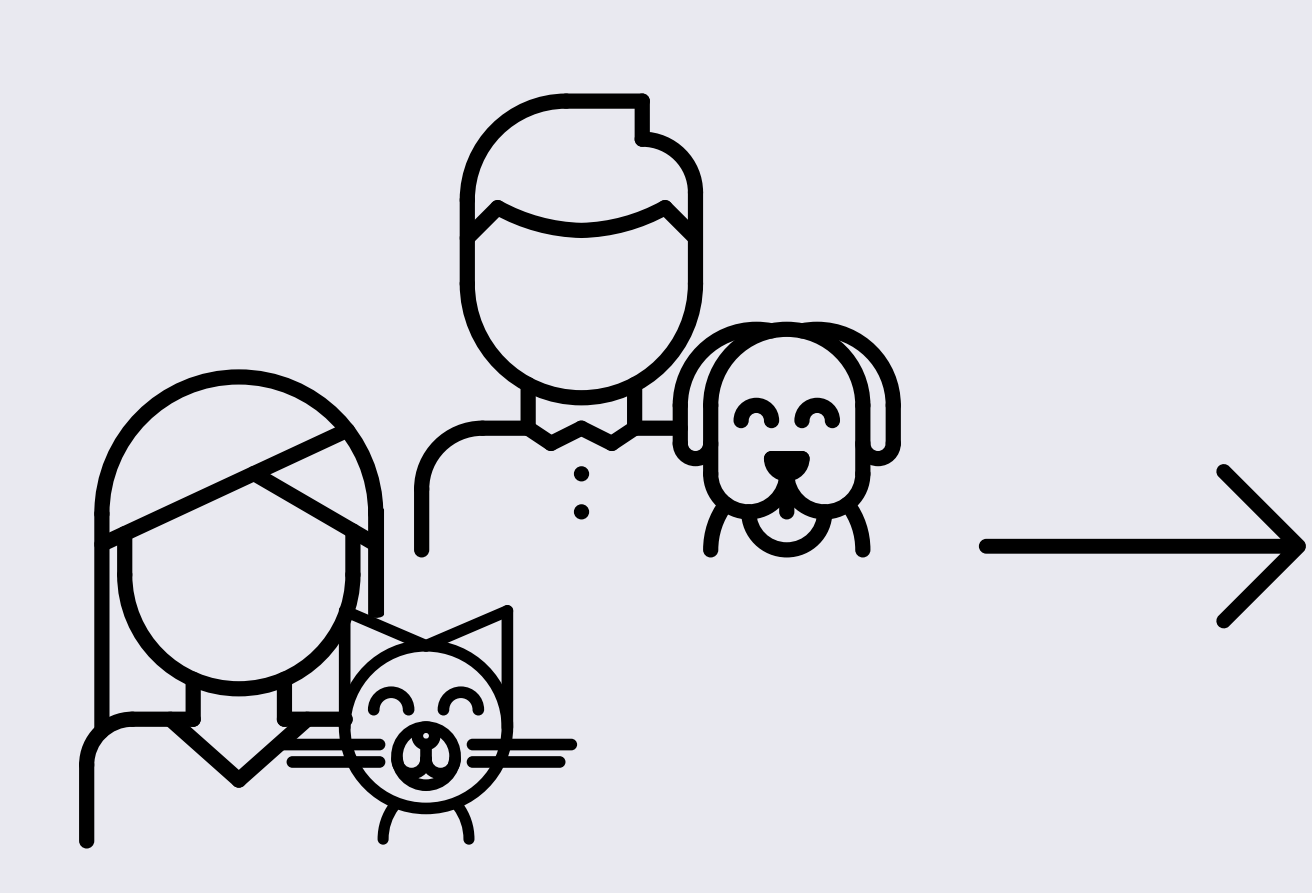

Students and staff of the Cummings Veterinary Medical Center at Tufts University with no prior training or experience using chambers were recruited.

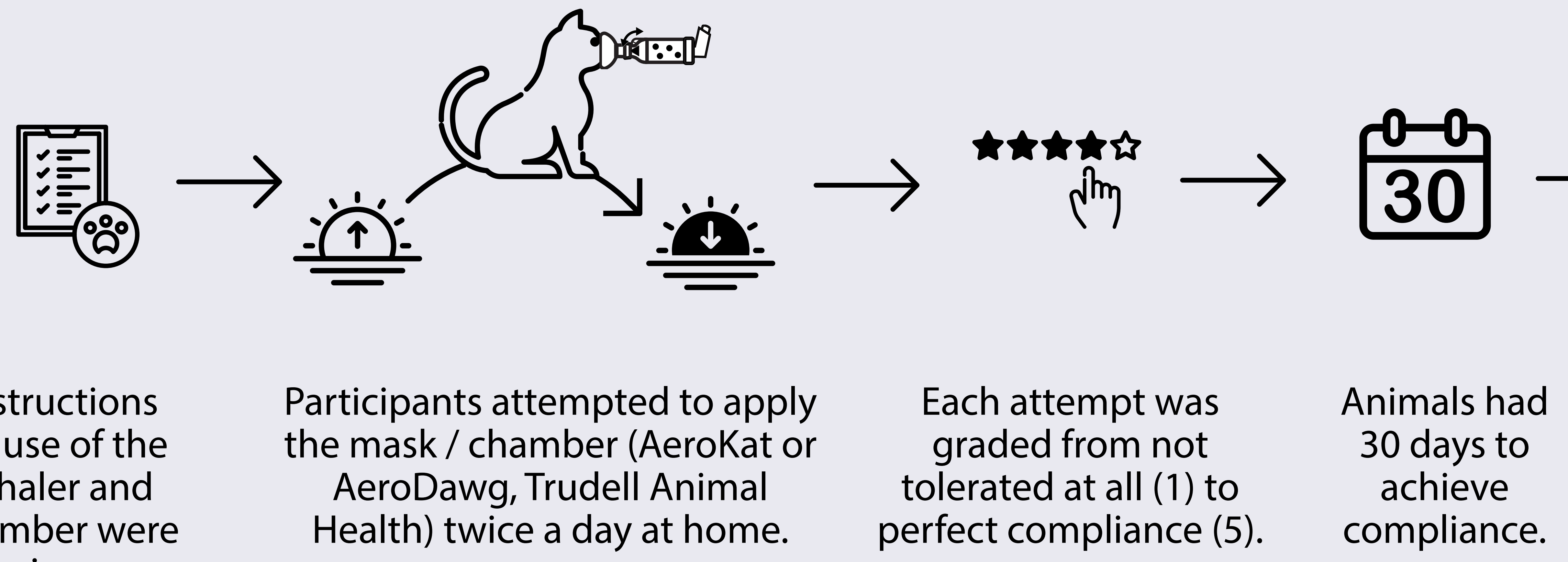

AeroDawg, Trudell Animal

chamber were Health) twice a day at home.

30 days to
achieve
compliance.

Compliance was defined by acceptance of the mask / chamber with minimal or no restraint (grade 4 or 5 ) for at least 10 breaths for 4 separate treatments.

\section{RESULTS}

\begin{tabular}{|c|c|c|c|c|}
\hline Species & $\begin{array}{c}n \\
(\#)\end{array}$ & $\begin{array}{l}\text { Acceptance } \\
\text { Rate }\end{array}$ & \multicolumn{2}{|c|}{$\begin{array}{l}\text { Median Time } \\
\text { to Compliance }\end{array}$} \\
\hline Dog & 22 & $100 \%$ & $\frac{0-0}{4}$ days & (2-18 days) \\
\hline Cat & 22 & $90 \%$ & $\begin{array}{c}0-0 \\
6\end{array}$ & (2-19 days) \\
\hline
\end{tabular}

22 dogs and 22 cats were enrolled. All dogs were cooperative with a median time to compliance of 4 days (2-18 days). $90 \%$ of cats were compliant by 30 days, excluding 2 which were non-compliant. The median time to compliance was 6 days (2-19 days).

\begin{tabular}{c|c}
$\begin{array}{c}\text { Student / Staff } \\
\text { Participants }\end{array}$ & $\begin{array}{c}\text { \% That Would } \\
\text { Now Recommend }\end{array}$ \\
\hline 44 & $100 \%$ \\
\hline
\end{tabular}

All participants reported that they 'definitively would' or 'most likely would' recommend an inhaler to their (future) clients.

\section{IMPACT}

Training to chamber acceptance can be easily performed in dogs and almost all cats.

Steps for training a cat or dog to use an inhaler and mask / chamber

$$
\text { (1)' CONDITION O LOVE מ子 REWARD }
$$

Concerns over potential challenges of mask / chamber training should not influence medical recommendations to manage lower airway disease with inhalation therapy as a safer alternative to systemic treatments.

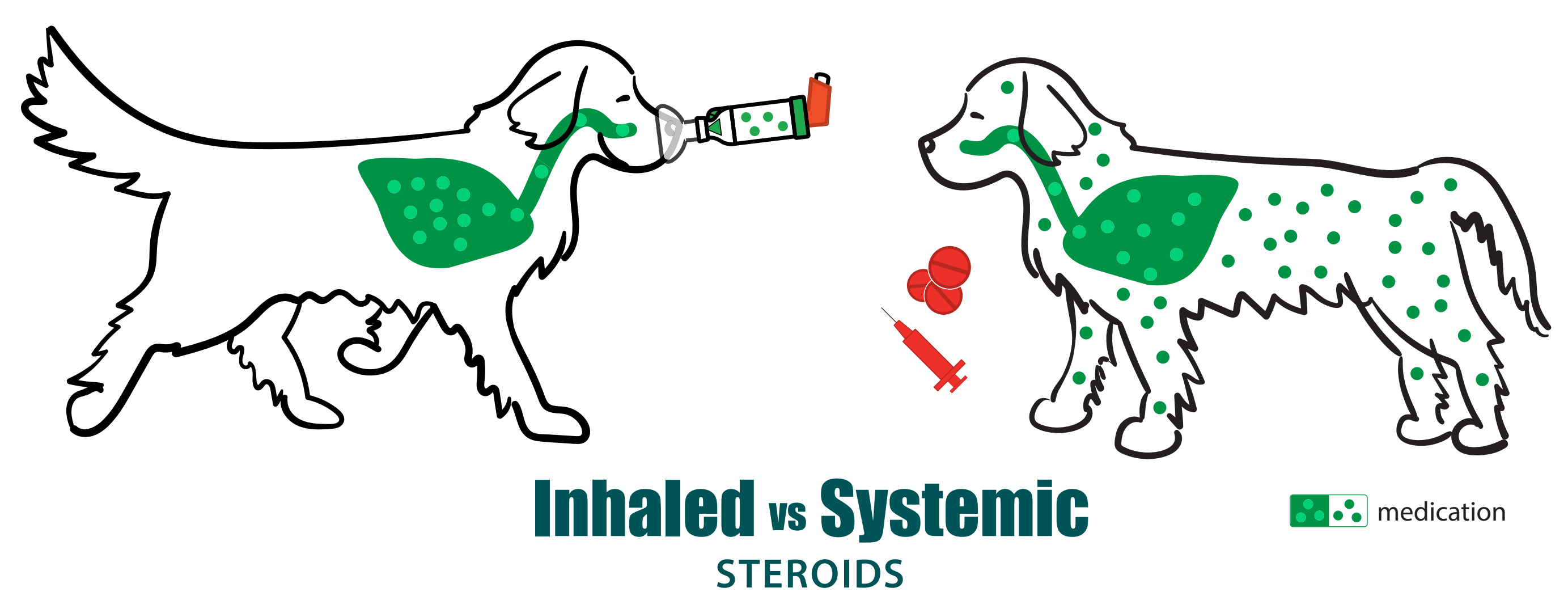

